\title{
Diversity Management in the Canadian Workplace: Towards an Antiracism Approach
}

\author{
Vanmala Hiranandani \\ Metropolitan University College, Copenhagen, Denmark \\ Correspondence should be addressed to Vanmala Hiranandani, vanmala_hi@yahoo.com \\ Received 21 March 2012; Revised 28 August 2012; Accepted 15 September 2012 \\ Academic Editor: Michelle Thompson-Fawcett
}

Copyright ( $) 2012$ Vanmala Hiranandani. This is an open access article distributed under the Creative Commons Attribution License, which permits unrestricted use, distribution, and reproduction in any medium, provided the original work is properly cited.

\begin{abstract}
Most diversity management programs in Canada maintain that enhancing workforce diversity is of tremendous significance for business organizations in today's competitive global urban markets. Since well-meaning diversity management initiatives have been largely ineffective thus far in dealing with workplace discrimination and racism in the Canadian workplace, this paper underscores the need to decenter the focus of diversity management from a business imperative to an antidiscrimination and social justice imperative. Within this latter perspective, the paper examines the strengths and limitations of the antiracism approach that has been implemented in various developed countries in recent years. The antiracism approach is an action-oriented strategy for institutional and systemic change that has at its core the interrogation of privilege, power disparities, and other forms of inequity within the organization. Drawing from the lessons of various initiatives that have utilized this approach, the present paper emphasizes the need for a nuanced antiracism approach in the multicultural Canadian society if diversity management is to attain its goal of greater inclusion of all individuals in informal networks and formal organizational programs.
\end{abstract}

\section{Introduction}

Human resource management has always been challenged with managing diversity although the exact nature of these challenges has varied over time. While the concern in earlier stages of industrialization was on managing class divisions, with increasing cultural diversity in contemporary times, the focus has shifted to managing diverse identity groups in the urban workplace [1-4]. "Diversity management" has emerged as a more popular alternative compared to employment equity and affirmative action. As a voluntary corporate approach that is perceived to enable organizations to capitalize on the benefits of workforce diversity, diversity management is less controversial. Indeed, diversity management has become a popular term, often under the rubric of corporate social responsibility (CSR) in many multinational corporations, and largely refers to hiring visible minorities and increasing cross-cultural awareness and communication. It is viewed as playing an important role in reducing turnover and absenteeism, attracting competent workers, enhancing creativity and innovation, bringing about attitudinal changes, and creating greater inclusion of all employees into organizational structures [5].

In today's global urban business environment, building a more diverse workforce that brings in different perspectives, experiences, insights, and international and multicultural contacts is increasingly being recognized as crucial to enhancing organizational competitiveness and effectiveness (e.g., $[2,6,7])$. A diverse workforce can maximize talent and creativity and foster innovation, which can ultimately lead to increased profits and positive public image for a successful business enterprise. While diversity has various meanings, the focus of this paper is on racial and ethnic minorities and their treatment in the workplace in the Canadian context $^{1,2}$. Canada is known for its multiculturalism and for being a refuge for people from diverse cultural backgrounds. Although business literature points to the fact that increasing diversity makes business sense, visible minority employees continue to face discrimination in the Canadian workplace.

This paper reviews various strands of diversity management in Canada: it is found that the business imperative for diversity and strategies to enhance workforce diversity 
form the bulk of diversity management literature in the country. While recent years have seen an increase in diversity and cultural competence initiatives, these strategies do not address racism in the workplace, and their impact has been limited in terms of retaining visible minority employees. Following a critique of current diversity management initiatives in the Canadian context, this paper examine the strengths and limitations of the emerging antiracism approach that has been tried in several urban locales and is considered more potent to tackle racism in the workplace and in the larger society of which the workplace is a part. After assessing the major principles underlying the anti-racism framework, the paper ends with suggestions for its nuanced adoption in the Canadian context to create a more inclusive and nondiscriminatory work environment.

\section{Diversity Management in Canada: An Overview}

The concept of diversity management originated in the USA in the 1990s following the growing need to manage crosscultural and individual differences in an increasingly diverse demographic workforce $[8,9]$. Diversity management has been embraced by many organizations in the USA where it has become multimillion dollar consulting business. As in the USA, in Canada, immigration and large numbers of women entering the workforce promoted diversity management efforts since the 1990s, although the workplace composition differs from that in the USA [10]. While several definitions of diversity management have been posited, the most common definition is that put forth by Gilbert et al. ([11, page 61]): "Diversity management is a voluntary organizational program designed to create greater inclusion of all individuals into informal social networks and formal company programs." A more practice-oriented definition is provided by Bassett-Jones [12] for whom diversity management refers to systematic efforts and planned commitment on the part of organizations to recruit and retain employees with various backgrounds and abilities.

The concept of "diversity" refers not only to demographic and cultural differences, but "a workforce made... distinct by the presence of many religions, cultures or skin colors, both sexes (in non-stereotypical roles), differing sexual orientations, varying styles of behavior, differing capabilities, and usually, unlike backgrounds" (Canadian Institute of Chartered Accountants and Society of Management Accountants of Canada, 1996 quoted in [10, page 307]). Contrary to the USA, where consultants initiated the discourse on diversity, in Canada, government agencies have taken the lead in enhancing public awareness of diversity issues [10]. And in contrast to the US that has espoused the "melting pot" approach, Canada adopted the policy of multiculturalism in 1971 [13]. The multiculturalism policy stresses the importance of providing services in languages other than English and French, "celebrating" diversity, and challenging dominant norms about dress code, food habits, accents, and other overt forms of prejudice. The policy of multiculturalism did, therefore, officially recognize Canada's mosaic of cultures and espouse the idea that racial/ethnic minorities have the right to maintain their cultural heritage. Multiculturalism resulted in organizations hiring visible minorities in entry-level positions primarily since they spoke a language that was required to serve a particular community.

Another initiative by the Canadian government to enhance labor force diversity is the federal Employment Equity Act (EEA) which is akin to Affirmative Action in the US and was first passed in 1986. The EEA covers the public sector as well as any private sector firm that contracts with the government and has more than 100 workers in Canada and government contracts valued at more than $\$ 200,000$ [14]. The EEA requires efforts by employers in covered sectors (e.g., communications, transportation, and banking) to reduce disparities in employment and workforce representation between designated groups (such as women, visible minorities, aboriginal peoples, and people with disabilities) and the general workforce [15].

While these policies laid the foundations for diversity management, the business sector's engagement with diversity management revolves around the twin rationale of the "business imperative" and the need to address shortages of skilled labor force. The "business imperative" argument lists several compelling reasons for increasing diversity in Canadian organizations.

(i) Fostering creativity and innovation: in the present-day urban business environment, characterized by globalization, rapid change, and uncertainty, companies must adapt, change, and learn at an unprecedented pace in business history. In such a rapidly shifting milieu, creative ideas, knowledge, and innovation are the only stable sources of capital [16]. Developing a more diverse workforce assumes enormous significance in a competitive market situation due to its potential to harness a variety of perspectives, experiences, and insights, which is vital to business success. Diversity in the workforce has been considered essential to maximize access to the pool of talented people $[6,17]$.

An organization's capability to innovate provides the cutting edge in today's competitive world. Researchers have found that groups composed of people from diverse cultures are more likely to bring a wider range of perspectives to the table that can generate more ideas and alternatives than a homogenous group $([6,16]$ Rousseau, 1995 cited in [7]). Oliver cites the example of Xerox Canada research center in Mississauga, Ontario, that employs 150 personnel from 36 different countries. The company's diversity has attracted the top scientific talent from around the world which has enabled it to capture more than 100 US patents. Additionally, since a diverse group tends to understand and communicate with each other differently, it is forced to proceed more carefully to reach a consensus. The outcomes are more carefully deliberated decisions and improved results.

(ii) Tapping new global markets: in an era of the globalized economy, businesses no longer operate in the national base. Global business is not limited 
to exports and imports; many companies depend on vendors, service businesses, and alliances and mergers in other parts of the world $[2,18]$. Enhancing workforce diversity has the potential to capture new global markets and thereby boost corporate success. Oliver [16] and Trichur [19] mention that foreign-born visible minorities living in Canada have knowledge of and connections to other countries which can be an invaluable asset in accessing overseas markets. Oliver [16] reasons that since currently more than one million people in Canada are of Chinese origin, tapping into this community could enable Canadian companies to gain greater access to Chinese markets, which today comprise only about five percent of Canada's exports.

(iii) Entry into ethnic markets: given Canada's changing racial and ethnic demographics, a company with a workforce that resembles its customer base is considered more competitive to gain greater entrée in the country's burgeoning ethnic markets. Oliver [16] provides the example of Bank of Montreal, which began to focus specifically on Chinese Canadians, that established Chinese branches across the country by hiring Chinese-speaking employees to understand the community's cultural nuances and as a result saw its business among this market segment increases by 400 percent over a 5 -year period.

Thus, the bulk of Canadian diversity management literature views diversity in the workforce as a business imperative to foster corporate and organizational success in the competitive global market. Shortage of labor is another compelling reason that has propelled Canadian companies to address diversity in the workforce. Severe labor shortages are expected in Canada during the next decade due to the retirement of the baby boomers and low birth rates, which will result in a ratio decline from about five workers for each retired person to about $2.5: 1[16,20]$. A pressing demand for labor, particularly skilled labor, exists in all sectors, including retail, manufacturing, and service industries.

The demand for skilled labor has led to liberal immigration laws that admit 200,000 new immigrants to Canada each year. About 70 percent of recent immigrants to urban Canada are visible minorities; people of color make up nearly 50 percent of populations in Vancouver and Toronto and are the fastest growing communities in Canada's eight largest cities [21, 22]. Fifty-four percent of these newcomers have professional skills, university qualifications, or have met specified business criteria, a rate that surpasses the Canadianborn population [16]. Oliver further informs that while visible minorities constituted less than 11 percent of the labor force on an average between 1992 and 2001, they accounted for as much as a third of the labor force's contribution to the country's gross domestic product (GDP) growth. Undoubtedly, Canada's workforce growth and, consequently, a significant share of its economic prosperity have come to depend on new immigrants. This trend has continued and it has been estimated that in 2011, 100 percent of the net labor force growth depended on immigration; visible minorities will comprise about 20 percent of the country's population by $2016[16,21]$.

These factors have led to increasing recognition of diversity by several Canadian companies. For instance, RBC Financial Group has ensured that $22 \%$ of their workforce is comprised of visible minorities, which is laudable. Telecommunication giants, such as Telus and Rogers, have set examples of recruiting diverse employees [21]. Similarly, FedEx has a high proportion of visible minorities (almost 7\%) in senior management positions. Its staff represents about 19 nationalities at its Mississauga, Ontario headquarters [23].

While these efforts are commendable, programs to hire, retain, and treat diverse employees fairly at the workplace are not widely prevalent in Canada. As the next section elaborates, visible minorities continue to face various forms of employment discrimination even in large multicultural cities.

\section{Ongoing Workplace Discrimination against Visible Minorities}

Several research studies have reported that labor market outcomes, employment, unemployment, weeks worked, and representation in better-paying jobs for visible minorities are poorer when compared with nonvisible minorities in Canada. Research has shown that access to job opportunities, upward mobility, earnings, and income have also been poorer (e.g., [24-26]). The unemployment rate for visible minorities has been persistently higher than that of the total population [27]. In 2006, visible minorities represented $15.4 \%$ of the labor force, up from $6.4 \%$ in 1986 [28, 29].

The disparity in average wages between visible minorities and Caucasian Canadians is alarming. K. R. Pendakur and K. R. Pendakur [24] found varying earnings differences for different ethnic groups and confirmed that Blacks experienced the largest earnings gap. Further, K. R. Pendakur and K. R. Pendakur [24] note that the earnings gap for visible minority workers aged 25-64 years has not only been persistent but has also been steadily increasing over the past 25 years. Oliver's [16] research showed that visible minorities earned 11 percent less than the Canadian average in 1991. This gap increased to 14.5 percent in 2000 . The differences in earnings for visible minority workers were due to fewer weeks of employment and lower earnings per week $([26,30])$.

It is noteworthy that education levels of visible minorities are not translating into comparable returns in employment. Samuel and Basavarajappa [26], drawing on Canadian Race Relations Foundation report, Unequal Access, stating that almost half of visible minority workers aged 25-34 years had university degrees compared to just over a quarter among the nonvisible minority workers of same ages. About a third of visible minority workers aged 35-64 years had university degrees compared to a fifth among the non-visible minority workers. Thus, visible minority men and women have higher educational qualifications, but their shares in the top income quintiles were less than those of the non-visible minority counterparts, demonstrating that their earnings do not match their educational attainments. The Conference Board 
of Canada [19] estimated that due to their unrecognized learning, visible minorities lose between $\$ 2.2$ billion and $\$ 3.4$ billion per year.

Furthermore, research reveals that visible minorities are underrepresented in the upper echelons of Canadian organizations $[15,16,19]$. According to the Employment Equity Act Annual Report, only $14.5 \%$ of individuals employed in the federally regulated communications sector are visible minorities and only $5.1 \%$ of senior managers working in the federally regulated private sector in 2006 were visible minorities [31]. Only 13\% of leadership positions in the Greater Toronto Area are held by visible minorities. The greatest number of leadership positions held by visible minorities is in the education sector (20\%), while the smallest number of leadership positions held by visible minorities is in the corporate sector (4\%) [32].

The Conference Board of Canada's 2004 report titled The Voices of Visible Minorities: Speaking Out on Breaking Down Barriers found that, despite 20 years of enacting employment equity legislation, a "sticky floor" limits the opportunities for initial advancement of visible minorities, while a "glass ceiling" stops them from attaining top positions in organizations (cited in [19]). The concept of "glass ceiling" refers to the phenomenon where the increased numbers of visible minorities in the workforce are not matched by a corresponding rise in their representation in senior levels of management [7]. The Conference Board's report shows hiring and promotion barriers are creating a widening gap between policy and practice, which will adversely affect the Canadian economy in the future. Visible minorities made up only 1.7 percent of the directors on boards of organizations in 2003 despite the fact that skilled visible minorities were widely available in the labor force [19]. Similarly, Oliver's [16] survey found that among the sixty-nine medium and large companies that responded, only three percent have a visible minority $\mathrm{CEO}$ and only three percent of about 900 senior executives in the surveyed firms were visible minorities. The research also uncovered that nine in ten organizations do not have any plans to recruit visible minorities to the Board of Directors, even though a majority believed that it is important to have representation of visible minorities in decision-making positions in the organization.

The differences in labor force outcomes between the Canadian-born visible minorities and their non-visible minority counterparts who have similar human capital characteristics, such as education and language skills, seem to point to the existence of discrimination, which is corroborated by several studies. Visible minorities are significantly less satisfied with their careers than Caucasian Canadians and more likely to experience workplace barriers, lack of fairness in talent management practices, lack of role models, and other key factors influencing career advancement [33]. In 2002, almost one in four visible minority workers reported that they had experienced racial harassment or discrimination in the workplace [24]. In the Ethnic Diversity Survey, Statistics Canada [27] found that $56 \%$ of participants who perceived discrimination or unfair treatment identified that they most commonly encountered such treatment in the workplace, particularly during job applications and promotions.

The report by Conference Board of Canada suggests that the propensity for sameness, preservation of status quo, and underlying racism lead employers to often cite "lack of fit" as the rationale for not hiring or promoting skilled minority candidates [19]. Overt discrimination has reduced but subtle forms of discrimination continue to exist. Additional employment barriers cited in Conference Board of Canada's report and also in Oliver's [16] research include speaking with an accent; having foreign-sounding names; unfamiliarity with Canadian mores; lack of recognition of foreign credentials; higher performance expectations for minority candidates. Conference Board of Canada estimates that the failure to recognize foreign credentials will cost the Canadian economy $\$ 1$ billion [21].

In addition to barriers in the hiring process, several research studies have shown that North American organizational culture, with its everyday discrimination, is the main reason for high turnover among visible minorities (e.g., $[15,16,20,34-36])$. When capable minority employees see no opportunity to advance, they tend to leave the organization. Organizations thus not only lose trained employees, thereby leading to higher costs, but also face the possibility of decreased productivity and increased absenteeism [7, 37]. While companies place a great deal of importance on hiring visible minorities, they do not take adequate steps to retain them, thereby creating the "revolving door" syndrome-this happens when a visible minority person leaves the company when s/he experiences inadequate opportunities to advance due to discriminatory and biased practices and finds the company's environment to be uncomfortable. Oliver [16] summarizes from his findings that Canadian businesses are wasting much-needed talent that will adversely affect Canada's economy. In a similar vein, Conference Board of Canada's report emphasized that these barriers are not only a disservice to minorities, but they will "come back to haunt mainstream Canadians by eventually stalling the economy" ([19, para 1$])$.

Evidence about discrimination in everyday lives of racialized peoples in Canada is plentiful. Statistics Canada's [27] survey on Ethnic Diversity reported that more than 1.4 million Canadians reported being subject to racial discrimination. An Ipsos-Reid Survey of 2005 found that 17\% of Canadians have been victims of racism at some point [38]. Oliver [16] mentions one in five visible minority persons reported experiencing discrimination or unfair treatment in the last five years. The actual figures could be higher. The Canadian Human Rights Commission reported that racebased complaints represent $36 \%$ of all complaints filed under Canada's Human Rights Act (cited in [39]). The workplace is the most common location where racism is experienced [21].

\section{Diversity Management in Canada: Critical Perspectives}

Given that workplace discrimination and poor labor market outcomes persist for visible minorities despite diversity 
programs and initiatives by the Canadian government and several businesses, it is crucial to critically examine the official multiculturalism policy and existing diversity management efforts. Despite its proclaimed merits, Canada's official multiculturalism policy did not reduce racial inequality $[22,40]$. Critics of multiculturalism have long observed that the policy of multiculturalism is superficial and does not question the more covert forms of control and ways of maintaining power in the workplace [40,41]. Boyd [42] observes multiculturalism policy merely grants cultural identities equal footing in the private sphere, but it receives a very low level of government funding for multicultural activities including antiracist educational initiatives. Multiculturalism maintains the myth that all cultures in Canada are equal, despite the power of the dominant culture to shape Canadian norms, values, and policies [22]. Writing about White Canadians' thoughts about multiculturalism, Yee and Dumbrill [22] cite interviewee comments that Canadian culture should "be first" and that multiculturalism was "dividing the country" (page 110). These anecdotes point to the larger, historical, collective structures embedded in Canadian consciousness. Homi Bhabha points to the unstated meaning underlying multiculturalism as "sham universalism that paradoxically permits diversity [and] masks ethnocentric norms, values and interests" (quoted in [43, page 485]). Multiculturalism, thereby, takes discussions on race and racism off the agenda, consequently further obscuring critical reflections on historical and contemporary privilege, power, and racial oppression.

Furthermore, research indicates that the Employment Equity Act has been ineffective in meeting its goals for ethnoracial minorities $[14,15,20,39]$. Unlike the disabled or aboriginal population, ethnoracial minorities who are new immigrants constitute a moving target since their population has been growing and varies across provinces. Attaining equity for ethnoracial minorities in the workforce is, therefore, more challenging than equity for other designated groups. Employment equity policy has been disapproved by both the white male majority and intended beneficiaries including women and minority groups. $\mathrm{Ng}$ and Burke [5] note that white males perceive employment equity practices as compromising the principle of merit in pursuit of numerical targets, while women and minorities have disassociated themselves from equity policies due the stigma associated with the perceptions that people hired under employment equity are incompetent and less qualified.

Moreover, while studies have established that large companies have higher levels of employment equity attainment, ethnoracial minorities continue to be disadvantaged in management, sales and service, and technical positions as well as in certain sectors covered by federal legislation, such as transportation and communication [15].

Even in the public sector, the federal government admitted that efforts to recruit more visible minorities are falling short, although targets for other designated groups (Aboriginal people, women and people with disabilities) are largely being met $[14,44]$. In the private sector, Trevor Wilson, president of diversity consulting firm, TWI and author of Diversity at Work: The Business Case for Equity, commented that many organizations doing work for the federal government "either find ways to get around the law or simply ignore the requirements" (quoted in [14, page 9]). Wilson mentions private sector firms sign EEA compliance certificates every year hoping that they will not get audited. The government does not have an adequate number of auditors which enable these firms to get away from the law. Moreover, it has been recognized that with changing times, the business imperative for diversity and equity is far greater than the goals and expectations specified in the EEA $[14,15]$. As such, recruiting and maintaining a diverse workforce needs to go well beyond the targets mandated in the legislation. Besides, the EEA is limited to government organizations and private sector firms that enter into contracts with the government. As such, the Act does not cover all organizations, leaving diversity initiatives to the business and/or equity sense of employers. Thus, few Canadian companies have efficient programs to build and utilize the talents of a truly diverse workforce. Again, most initiatives only attract visible minorities (some of them to comply with Employment Equity legislation); many of them are inadequate in retaining minority employees.

To its credit, the Canadian government initiated the Racism-Free Workplace Strategy (RFWS) as a key part "A Canada for All: Canada's Action Plan Against Racism" in 2005. Aiming to augment the effectiveness of the EEA, the goal of the RFWS is to remove the systemic discriminatory barriers faced by both visible minorities and Aboriginal peoples. RFWS focuses on increasing awareness about racismrelated issues in the workplace and building strong partnerships with organizations, employers, and unions [45]. In 2007, RFWS delivered 75 Racism-Free Workplace workshops to 515 private sector employers throughout Canada [46]. In 2008 nine regional Racism Prevention Officers were hired to work with employers and stakeholders directly.

Evaluation of the program is still ongoing and in progress; hence it is too early to assess the outcomes. Results from workshops have shown the need for tools to address racism (OAS, undated).

In the business sector, most diversity management programs involve cross-cultural training to understand differences in cultures, religions, and customs. In the global economy, increasing emphasis is being placed on the need to develop "cultural competence" defined as "the skill to bridge the cultural dimensions of human behavior" ([2, page 210]). The importance placed on the need for managers to be equipped with knowledge about diverse ethnoracial communities emanates from the belief that ignorance and prejudice about cultures different from one's own can lead to cultural insensitivity and discrimination. Hence "cultural competence" programs are based on the belief that if one can better understand the behavior, culture, and perspectives of another ethnoracial group, then cultural respect and acceptance should follow.

Although cultural competence models are well intentioned, in the diversity literature reviewed for this paper, many writers who advocate for diversity in the business field do not question institutional and societal racism of which the workplace is a part. The underlying assumption of most 
diversity and cultural competence initiatives appears to be that corporate leaders and managers need to be persuaded that people who look or act differently can be of much use to the organization, and, therefore, managers only need to educate themselves about "others" $[22,40]$. Educational sessions in diversity programs are seen as the way to provide "socially dominant groups in the organization with selected pieces of information about others, so that they can be brought into an organization, which remains essentially unchanged" [40, page 12]. Information on differences between cultures is highlighted and imparted in cross-cultural training sessions often conducted by White people. A focus on understanding culture creates several problems. Firstly, this approach diverts attention from the lived experiences of minority groups since their voices easily become secondary to the dominant culture that presents itself as nonideological, fair, and neutral but retains the power to define societal and behavioral norms against which minority cultures are compared [22]. Secondly, although a focus on culture and diversity can make us feel good about acquiring knowledge regarding another culture, this approach undermines the shared responsibility to dismantle systemic, individual, and discriminatory barriers in the workplace. Finally, at its worst, diversity training and cultural competence programs can be reductionist by relegating "culture" to a static concept that is reduced to celebration of dress, cuisine, customs, and behaviors of various cultural groups.

Moreover, Wong et al. [47] observe that a review of literature on cultural competence reveals a few common conceptions of culture. Culture frequently refers to "the sum total" or "totality" of "ways of life" or "life patterns": Henry, Tator, Mattis and Rees (1995) define culture as "the totality of ideas, beliefs, values, knowledge, and way of life of a group of people who share a certain historical, religious, racial, linguistic, ethnic or social background" (quoted in [47, page 150]). However, as Dean [48] reminds us, culture is individually and socially constructed, and cultural identities are fluid and dynamic since they are continually changing and evolving. From this perspective, the growing popularity of cross-cultural awareness sessions runs the risk of stereotyping cultures, which can be as damaging as ignorance, as Locker and Findlay [2] admit. Becoming "culturally competent," then, becomes a challenging prospect since it is questionable if one can become truly competent at the culture of another. Dean [48], therefore, proposes a model based on acceptance of one's lack of competence in crosscultural matters, which acknowledges that our knowledge is always partial. From this perspective, our goal must be not as much to achieve competence as to participate in the ongoing processes of building relationships and understanding the contexts and histories within which cultures develop.

The assumption of cultural "totality" in the conceptualization of values, beliefs, and behaviors of various cultural groups also masks the ambiguous, conflicting, and contradictory meanings of culture that are mediated by power. Understanding power relations is, thus, critical to understanding culture [49]. Dean [48] emphasizes that it is not just rituals, traditions, norms, values, and beliefs that influence the functioning of a member of a cultural group, but also the way that group is treated within the larger society. This treatment emanates from various racial ideologies prevalent in the larger society that attribute particular cultural traits to certain groups. This sociopolitical analysis necessitates an inquiry into the various forms of oppression that have resulted in racial and economic stratification and limited opportunities for ethnoracial minorities in the workplace. A limited focus on gaining "competence" in the beliefs, customs, and historical traditions of different cultural groups can veil the oppressive power relations between groups and the ways in which dominant groups are positioned to control other groups in society. The fervor with which theories of cultural competence are adopted in contemporary organizations while racism remains unnamed is a reminder that culture is treacherous ground to travel in an oppressive society [50].

Racism in Canadian society is important to name, recognize, and understand to build a truly inclusive workforce and nondiscriminatory work environment. Racism is defined as those aspects of society that "overtly or covertly attribute value and normality to White people and Whiteness and that devalue, stereotype, and label racialized communities as other, different, less than, or render them invisible" ([40, page 270]). According to Sintonen and Takala [18], a certain ideology is at the core of racism-this ideology states that the outward appearance of people defines their capabilities and position in society, with skin color as the most important signifier. The hidden function of this kind of ideology is to secure and guarantee the prevailing social order and division of power $([18,40,50,51])$. Actions, language, and behaviors that are ideologically based on racism entail discriminating practices in organizations and society. These discriminating practices isolate visible minorities from the resources provided by society and the economy [18].

Boyd [42] emphasizes that attitudes say little about levels of discriminatory behavior: she mentions Canadian politeness may simply ensure that discrimination is hidden or covert. Overt racial slurs and derogatory remarks are not frequently heard in current times; however, blatant racism (although not completely nonexistent) has been replaced by more subtle forms of racism in terms of institutional practices $[34,35]$. Institutional racism is defined as "the network of institutional structures, policies, and practices that create advantages for White people and discrimination, oppression and disadvantage for racialized people" ([40, page 270]). These subtle forms of racism allow individuals to hold discriminatory views while defending such views with nonracially based rationales. Brief et al. [34] give an example where a Black candidate is not rejected for a sales position based explicitly on the employer's distaste for working with Blacks; rather the employer rationalizes that a black salesperson may not be a "good fit" for a White customer population. Because people do not view themselves as "racists," they are unlikely to engage in overt expressions of prejudice, such as racial slurs, but they do engage in more subtle discriminatory behaviors, such as avoidance of visible minorities and closed and unfriendly verbal and non-verbal communication. Thus, the modern nature of racial attitudes suggests that focusing only on blatant discriminatory 
acts is inadequate to fully understand the experience of discrimination [35]. Overall, critical writings on diversity management and multiculturalism in the Canadian context resonate with emerging international and critical literature that suggests that the discourse of diversity as a corporate social responsibility obfuscates race relations and power, that it reproduces social hierarchies and representations of identities based on binaries and that it is merely a business imperative for attracting global capitalism and exploiting hitherto untapped market segments (see [52-55].

\section{An Alternative Framework: The Antiracism Approach}

Most diversity discourse and research in North America have been instrumentally driven and mainly focused on advocating the business case for diversity: the more sophisticated diversity management programs view employees as strategic assets in organizations, while aligning diversity values with the organization's goals and business strategies [53]. With the focus on the benefits of diversity to organizations, current diversity management practices are not intended to guarantee the integration of minorities in a dominant culture.

Keeping in mind the limitations of current diversity and multicultural initiatives, critical theorizing on diversity, particularly originating from the European Union, has begun to question the business case strategies, particularly the assumptions regarding the nature of diversity, approaches to "manage" diversity, and the argument that diversity must be "capitalized" upon (Walby, 2007 quoted in [53]). One strand of this critical theorizing questions the essentializing of sociodemographic categories, such as race, ethnicity, and gender. These scholars maintain that representing sociodemographic categories as fixed essence and binaries (e.g., male/female; able-bodied/disabled; ethnoracial minorities/Caucasians) marginalizes differences of specific categories and pays inadequate attention to individual or within group variation. Hence, these writings emphasize the fluidity of diverse identities in organizations and the importance of social and organizational contexts and how they shape the dynamics of managing diversity (e.g., $[52,56,57]$ ). A second and related strand emphasizes the need to examine diversity within existing interlocking power structures and relations and in differing social constructions of diversity values and priorities [53]. Risberg and Søderberg [54] note that their research and several Danish studies point to a social responsibility aspect of diversity management that is rarely found in North American or British literature. Several discourses of human rights, justice, antidiscrimination social responsibility and diversity as a business case are intertwined in the diversity policies of frontrunner Danish firms, which emphasize care, peer support, and personal development together with the business advantages of diversity. However, Risberg and Søderberg also point to the need to distinguish between the discourse of diversity in strategic corporate communication and the actual implementation in a company's daily social practices pertaining to diversity.
Within the antidiscrimination framework, several Canadian scholars and consultants on equity in the workplace have advanced the concept of anti-racism that poses pointed questions about power disparities and other forms of inequity (e.g., [40]). Dei [58] puts forth a comprehensive definition of anti-racism as an action-oriented strategy for institutional systemic change that addresses racism and other interlocking systems of social oppression. It is a critical discourse of race and racism in society that challenges the continuance of racializing social groups for differential and unequal treatment. Antiracism explicitly names the issues of race and social difference as issues of power and equity, rather than as matters of culture and ethnic variety (page 252).

While the concrete steps of an anti-racism approach would depend on the workplace culture and dynamics of each organization, there are certain common principles underlying this framework. Firstly, the antiracism approach asks unsettling questions about the emphasis placed on people's ethnocultural differences and interrogates the ways in which organizations are structured to reinforce inequities [40]. In contrast to "cultural competence," the growing antiracism movement scrutinizes "systemic racism"-a term used to refer to the ways in which racism is produced and reproduced by seemingly normal ways in which work is structured, monitored, and rewarded. Racism is, thus, seen as a by-product of apparently neutral procedures of doing business. For example, studies have shown that recruitment processes often screen out people of color who do not have the same background as White people who were recruited in the past [7].

Anti-racism acknowledges that inequitable power relations exist in society and permeate every sphere. True and lasting equity can be possible only by taking a reflective, honest, and critical look at the ways in which the normal, apparently neutral mechanisms of most organizations benefit the dominant group and disadvantage visible minorities [40]. Analyzing an organization's systems is thus an invitation to take an honest look at various aspects of the organization such as hiring, promotion, allocation of job responsibilities, employee satisfaction, turnover rates, organizational culture, and other everyday practices. This process of self-analysis recognizes that employment systems may not always reward competence and hard work and may be vulnerable to favoritism and bias.

Secondly, the anti-racism framework believes that modern racism exists in ways that may be hard for those who do not experience it to fully understand. Members of the dominant culture often discourage alternative perspectives by simply ignoring or denying the relevance of other groups' experiences with racism $[7,22,50]$. Anti-racism educators firmly believe that the dominant group must be educated to recognize that they do indeed live in a different world than racial minorities and that the latter's experiences may be fundamentally different from their own. This can trigger dialogue instead of shutting down conversations about racism. Through dialogue the visible majority and minority groups can become more aware of each other and themselves, which enhances the possibilities for working together toward common goals. 
Thirdly, and arising from the second principle, antiracism equips the dominant group with knowledge and skills to acknowledge their own privilege and to work towards social change. In the Canadian context, a focus on White identity is the crux of anti-racism work, according to Yee and Dumbrill [22] who explain "to examine Whiteness is to identify how race shapes the lives of both White people and people of color" (page 100). Elaborating on the dimensions of Whiteness, Frankenberg (1993) (cited in [22, page 103]) noted that firstly, Whiteness is a location of structural advantage or privilege. Secondly, it is a "standpoint"—a place from which White people look at themselves, at others, and at society. Thirdly, "Whiteness" refers to a set of cultural practices that are usually unmarked and unnamed. The essence of Whiteness, thus, lies in its potency to maintain a silent assumption that equates normality with White culture, which becomes the taken-for-granted norm.

Therefore, proponents of anti-racism approach believe that any racial equity work must ensure that people with power have opportunities to examine their own experiences of unearned privilege. Peg MacIntosh defines unearned privilege as "the invisible knapsack of unearned assets which White people can count on cashing in each day, but about which they are meant to remain oblivious" (quoted in [40, page 272]). Examples include the ability to be unaware of race; the assurance that police will not stop or harass them because of their race; the assurance that they will not be followed in a store; the assurance that they will not be harassed, hated, or intimidated in the community; the assurance that they will not experience surveillance from their neighbors or police; the assumption that getting hired or promoted is due to their competence and not because of their race. Lopes and Thomas [40] further mention that White people must also grapple with the difficult question of why they would want to share the power they hold. This can lead to innovative solutions to address the discriminatory work culture.

Finally, this approach mobilizes the skills and knowledge of White and racialized people gained through the antiracism deliberations to question the status-quo and work towards a redistribution of power in organizations and society. For instance, White people can challenge employers on the number of White people hired as a result of networks and friendships. Racism, thus, is seen not only as a problem to be resolved by those it targets; it is also the responsibility of White people who benefit from this system to reject it [59]. Lopes and Thomas [40] inform that although this approach can lead to tensions and discomfort, the dilemmas that arise as a result can be used productively to build alliances and common cause among White and racialized workers.

The anti-racism approach has been applied in several settings in North America and elsewhere (see [60]). Here, four of such initiatives-Dismantling Racism; Project Change at Levi Strauss Foundation in the USA; Seattle City Government Race and Social Justice Initiative; Undoing Racism, New Orleans, USA-are reviewed and pertinent lessons are drawn for the Canadian milieu.
5.1. Dismantling Racism. Dismantling Racism (DR), coordinated by dRworks (originally called Changework), was initiated in the US as a systems change intervention strategy to address institutional racism in organizational settings. $\mathrm{DR}$ is a collaborative effort between anti-racism trainers, researchers/evaluators, community organizers and leaders working in partnership with organizations and communities. The pivotal characteristic of DR is that it is a process to assist leaders and organizations to understand and address racism, both within their organization and also in the community where the organization operates or is located $[61,62]$. The DR framework addresses institutional racism at three levels of an organization:

(i) at the individual level in terms of individual employee attitudes, beliefs, and behaviors;

(ii) at the intraorganizational level through the organizational structure, climate, and culture, including relationships between staff and organizational policies and procedures;

(iii) the extraorganizational level that includes the influence of external social, economic, political, and cultural factors that impact the organization.

More specifically, DR aims to increase the accountability of individuals and systems in monitoring health care inequalities and to develop a shared analytical framework to understand the underlying problems (see http://www .dismantlingracism.org/Dismantling_Racism/aBout_uS.html for details). A key element of the DR intervention is incorporating a change team, which is multiracial in composition consisting of a cross-section of employees within the organization, who work alongside DR consultants, evaluators, community representatives, and other stakeholders. The change team is responsible for monitoring and evaluating the impact of the intervention in terms of organizational policies, procedures and practices, allocation of resources, relationship structures, organizational norms and values, and individual skills and attitudes of staff.

5.2. Project Change. Developed by the Levi Strauss Foundation in 1991, Project Change is an initiative to address racial prejudice and institutional racism in four communities in the USA where Levis Strauss operates its facilities: Albuquerque (New Mexico), El Paso (Texas), Valdosta (Georgia), and Knoxville (Tennessee). Although Project Change has concluded, several of its anti-racism activities and networks continue to operate, both within some of the communities, as well as at a national level [63]. The organizing structure of Project Change included the formation of taskforces consisting of volunteer members from diverse groups. The initial goals of Project Change were to

(i) dismantle institutional policies and practices that promote racial discrimination;

(ii) ease tensions between minority and majority groups and reduce interethnic conflict; 
(iii) promote fair representation of diversity in the leadership of community institutions;

(iv) stop overt or violent acts of racial or cultural prejudice (Batten and Leiderman, 1995 cited in [60]).

According to the evaluation undertaken by the Centre for Assessment and Policy Development (CAPD), Project Change succeeded in changing policies and practices in some institutions, including the composition of boards and governing bodies. Tackling institutional racism was the project's biggest challenge, due to lack of clarity and significant resistance from some institutions. Taskforce leaders felt limited in their ability to reduce institutional racism. These challenges were compounded, given limited resources and the broader economic and political context for addressing institutional racism [63].

On the positive side, Project Change enhanced the national and internal dialogue on institutional racism by disseminating information to organizations, corporations, funding bodies, policy makers, and at meetings and conferences. The project also resulted in a number of publications and resources, including an online network and clearinghouse for anti-racism news and activities [63].

5.3. The Race and Social Justice Initiative (RSJI). The Race and Social Justice Initiative was initiated by the Seattle City Government in 2004 to address institutional racism in the city. The program is ongoing with the following aims:

(i) to assess the impact of race on organizational culture, policies, practices, and procedures,

(ii) to transform business practices towards race and social justice goals,

(iii) conduct outreach and create public engagement opportunities,

(iv) to provide training and build the capacity and skills of city staff to address institutionalized racism (Potapchuk and Aspen Institute Roundtable for Community Change, 2007 cited in [60]).

The RSJI initiative requires all city departments to develop a work plan to undo institutionalized racism and support multiculturalism; it requires that activities and findings must be reported directly to the mayor. In the first year of the program, review of department plans identified five common concerns: workforce equity, economic equity, immigrant and refugee services, public engagement, and staff capacity building [64]. RSJI developed a comprehensive organizing framework to manage and implement specific activities arising from these central concerns across departments. The Office for Civil Rights is responsible for managing implementation of RSJI: it reviews departmental plans, provides support to change teams, coordinates training and manages the staffing of the core team. The core team consists of approximately 30 employees who receive training to provide strategic planning, lead training/workshops for other city staff, and work on issues specific to the initiative. Change teams have been created within each department and they are responsible for implementing the RSJI plan supervised by a senior leader. The central concerns committee coordinates efforts across various departments, enables sharing of best practices, and develops tools and policies to address concerns raised within departmental plans (Potapchuk and Aspen Institute Roundtable for Community Change, 2007 cited in [60]).

An evaluation of the initiative found that the broad goals of the RSJI were disseminated and adequately understood by department managers and change team members. Most departments embraced the initiative and established change teams to develop and implement work plans [64]. The mayor's commitment resulted in increased reporting, development, and implementation of a capacity building and anti-racism training program targeted at change team members and managers [64]. Workforce equity activities were enhanced and these included the recruitment of people from diverse backgrounds at every level, particularly entry-level positions such as laborers and administrative assistants. However, the city has expressed its commitment to increase upward mobility and professional development opportunities for employees.

From 2009 to 2011, the City of Seattle expanded its commitment to racial equality: RSJI received full endorsement of all elected City officials. RSJI has been integrated as a core value into all the mayor's programs and priorities. The City's budget office requires departments to use Racial Equality as a basis to analyze every budget proposal in terms of impact of policy and program decisions, as well as unintended consequences. Seattle City Council requires all City departments to report on the progress of their annual Race and Social Justice Initiative work plans [65]. The City's 2012-2014 plan expands the RSJI to focus on ending racial inequality in the community and to strengthen partnerships across institutions and the community [66].

5.4. Undoing Racism. Undoing Racism is workshop offered by the People's Institute for Survival and Beyond, which is a national, multiracial, antiracist network based in New Orleans, USA, dedicated to eradicating racism and other forms of institutional oppression (http://www.pisab.org/). The institute provides training, consultation, and leadership development to organizations nationally and internationally. Workshops aim to enable participants to unpack racism, where it comes from, how it manifests and why it persists, and how to dismantle racism. Training materials include learning from history, developing leadership, ensuring accountability, establishing networking, undoing internalized racism, and understanding the role of organizational gatekeepers in perpetuating racism. Under the Undoing Racism program, the Community Organizing Strategy Team (COST) works with community activists to assess their organizations, roles, and relationships in terms of racial and cultural diversity. The Reflection, Assessment, Evaluation Team (RAE) enables the organization or group to articulate its vision, values, and goals and to measure outcomes in terms of the stated objectives. 
In the evaluations conducted, participants have rated Undoing Racism highly, with many participants expressing commitment to address institutional racism. For instance, Mack Burch et al. (2005) cited in Trenerry et al. [60] conducted an evaluation of Undoing Racism, undertaken as part of the Seven Principles project which conducted workshops with staff from health and social service agencies with the goal of eliminating disparities in African American infant mortality in San Francisco, USA. While 80 percent of participants rated the workshops highly, 90 percent agreed to undertake some form of action to tackle the effects of institutional racism. Many participants also mentioned that the workshops had impacted them on a personal level, and a number of them have adopted practices to improve cultural competency within their organization and to decrease institutional racism. Another evaluation of Undoing Racism was conducted by Johnson et al. [67] to evaluate training for community service providers to address disparities in child welfare. This evaluation found a high level of participant satisfaction with the training, increased knowledge of issues of race and racism, and increased awareness of racial dynamics [67].

Since organizations differ in their internal cultures, no cookbook recipes can be suggested for dealing with racism; however, there are significant commonalities in the aforementioned case studies in terms of intervention strategies, outcomes, and key learnings. It is interesting to note that although several of these interventions included diversity training as one of their components, authors such as Yee and Dumbrill [22] and Lopez and Thomas [40] maintain the distinction between the anti-racism approach and diversity training and cultural competence models: they emphasize that the anti-racism approach must acknowledge that racism exists in society and that conflicts between ethnoracial minorities and the dominant group are not due to lack of understanding between groups, but rather a manifestation of power differentials between the dominant group and racialized minorities.

In terms of positive outcomes, anti-racism initiatives have recorded improved representation of diverse employees; better staff seniority profiles; increased sales and productivity; increased retention of visible minority employees; more diverse composition of boards; improved awareness, knowledge, and skills; perceived fair treatment; acceptance of ethnic differences; reduced racial tension [60].

Several key learnings deserve attention. One of the most salient themes that emerged from the aforementioned initiatives is the need to be cognizant of resistance from some institutions as the effort required to reduce institutional racism becomes evident. Leadership was underscored as key to supporting institutional change, ensuring adequate resource allocation and persistent efforts, and engaging with those resistant to and/or fearful of change. Training for managers and staff emerged as significant in recognizing and addressing race-based discrimination and its consequences. The case studies also demonstrate that transforming the values and culture of individuals and the organization is a timeconsuming process and requires long-term commitment.
Importantly, anti-racism approach has been criticized for creating psychological discomfort for the dominant group. Strong emotions such as guilt, humiliation, sadness, shame, and embarrassment can result, leading to increased prejudice [68]. As this educator and author of the present paper experienced in her classrooms in US and Canada, students from the dominant culture may disengage from anti-racism discussions as they become overwhelmed with discussions of race.

Another risk entailed in the anti-racism approach is that it can mistakenly portray racism as mainly perpetrated by the dominant group, thereby creating a simplistic binary between visible minorities and the dominant culture and perpetuating an "us-versus-them" perspective. The atmosphere of alienation and bias against white people thus engendered can further widen the schism. The generic label of an "oppressor" may lead dominant culture participants to avoid interracial contact completely, deny their race, or resist learning about race and racism [69].

Likewise, discussions of the "unearned privilege" of the dominant group require considerable sensitivity as it may result in feelings of guilt, sadness, and embarrassment, which can lead to increased prejudice [69]. Where relevant, it is important to focus on the privilege itself rather than painting the entire dominant group with one stroke of brush as inherently racist. Similarly, evidence of racism committed by members of minority ethnic groups should be acknowledged, rather than being hushed or denied. Antiracism approach must encourage everyone regardless of racial, ethnic, cultural, or religious background to engage with experiences of privilege across other facets of their identity (e.g., gender and social class). This is particularly significant in a diverse and multicultural country such as Canada where intersecting differences and interlocking forms of oppression and privilege persist across race, gender, class, ethnic and religious backgrounds, Aboriginal/nonAboriginal status, age, disability, and so on.

Moreover, an anti-racism approach tailored to the Canadian context must be cognizant of the country's history in terms of colonial legacy, multiculturalism, and immigrantled growth. As such, firstly it is imperative for the Canadian version of anti-racism approach to build solidarity with the decolonization struggles of the original inhabitantsAboriginal peoples [70, 71]. Secondly, given the high rates of immigration and racism faced by new immigrants [27], educating participants about the geopolitical reasons for contemporary outmigration from other countries can reduce racism in the society and contribute to a better understanding of immigrants and their cultures. Finally, antiracism in the Canadian context must also debunk common myths, such as immigrants are taking away the jobs of the dominant group [72]. As stated earlier, visible minorities have contributed significantly to the country's economic prosperity [16]. Even today, Canada faces a shortage of skilled workers; moreover, many immigrants are employed in unskilled and low-paid jobs such as meat packing that are not filled by the dominant group. 


\section{Concluding Comments}

Despite the fact that diversity makes astute sense for organizational success, visible minorities face discrimination in the hiring process. They are paid less than the dominant group, and they face blocked opportunities in addition to racism in the larger society and community. While employment equity and diversity and cultural competence initiatives exist in many companies and organizations, they have largely failed to ensure equity and fairness in hiring, retention, and treatment of visible minorities. Most diversity programs in Canadian workplaces are limited in their scope. Attempts to increase the number of minority hires are inadequate unless they are also coupled with programs to deal with racism in the workplace. Discrimination continues to permeate organizations in subtle, nearly invisible forms due to stereotypical assumptions prevailing in organizational norms and everyday practices.

The importance of the anti-racism approach for organizational success cannot be overstated. The anti-racism framework takes up the challenge of building healthy, inclusive, and antidiscriminatory work environment. However, the anti-racism approach is not without challenges. This paper has highlighted the key dilemmas faced by anti-racism practice, and it has briefly suggested several directions to make this approach more suitable to the Canadian situation. Undoubtedly, further research and development in antiracism work in Canada are an urgent priority. Additionally, as Brief et al. [34] and Sintonen and Takala [18] remind us, organizations are not solely responsible for anti-racism efforts. Anti-racism initiatives in the workplace must be supplemented by efforts on a national scale with government officials, educators (including those in business, commerce, and management disciplines) and popular media taking the initiative to debunk the notions of skin color, ethnicity or religious background as markers of inferiority or superiority.

\section{Endnotes}

1. While diversity in the workforce originates from many sources such as gender, race and ethnicity, regional and national origin, social class, religion, age, sexual orientation and abilities [2,7], for the purpose of this paper the terms "diverse" and "diversity" refer to the inclusion of ethnoracial minorities. Given the space constraints in this paper, it is suggested that workforce participation of other diverse groups are important and complex topics that merit detailed and separate reviews of their own.

2. For the purpose of this paper, the term "visible minority" is defined as nonwhite, non-Caucasian people in Canada. This definition is used in the paper with full awareness that "visible minorities" are in fact the global majority. Visible minorities will form more than half of the populations of Toronto and Vancouver [2, 22]. The term "visible minority" is used in the paper for simplicity reasons to distinguish ethnoracial groups from other designated minority groups such as women, and people with disabilities.

\section{References}

[1] K. Hutchings, "Book review: managing diversity: toward a globally inclusive workplace," Asia Pacific Journal of Human Resources, vol. 43, pp. 430-431, 2005.

[2] K. O. Locker and I. Findlay, Essentials of Business and Administrative Communication, McGraw-Hill Ryerson, Toronto, Canada, 2006.

[3] G. Palmer, "Diversity management, past, present and future," Asia Pacific Journal of Human Resources, vol. 41, no. 1, pp. 1324, 2003.

[4] D. J. Terry, "Social identity and diversity in organizations," Asia Pacific Journal of Human Resources, vol. 41, no. 1, pp. 25-35, 2003.

[5] E. S. W. Ng and R. J. Burke, "Person-organization fit and the war for talent: does diversity management make a difference?" International Journal of Human Resource Management, vol. 16, no. 7, pp. 1195-1210, 2005.

[6] A. Ferner, P. Almond, and T. Colling, "Institutional theory and the cross-national transfer of employment policy: the case of 'workforce diversity' in US multinationals," Journal of International Business Studies, vol. 36, no. 3, pp. 304-321, 2005.

[7] M. Hamlet, The underrepresentation of Blacks in the executive suite in corporate America [Ph.D. dissertation], Walden University, 2000.

[8] T. H. Cox and S. Blake, "Managing cultural diversity: implications for organizational competitiveness," Academy of Management Executive, vol. 5, no. 2, pp. 45-56, 1991.

[9] S. Nkomo and T. Cox, "Diverse identities in organizations," in Handbook of Organizational Studies, S. R. Clegg, C. Gardy, and W. R. Nord, Eds., Sage, London, UK, 1996.

[10] G. E. Miller and J. I. A. Rowney, "Workplace diversity management in a multicultural society," Women in Management Review, vol. 14, no. 8, pp. 307-315, 1999.

[11] J. A. Gilbert, B. A. Stead, and J. M. Ivancevich, "Diversity management: a new organizational paradigm," Journal of Business Ethics, vol. 21, no. 1, pp. 61-76, 1999.

[12] N. Bassett-Jones, "The paradox of diversity management, creativity and innovation," Creativity and Innovation Management, vol. 14, no. 2, pp. 169-175, 2005.

[13] R. L. Tung, "The cross-cultural research imperative: the need to balance cross-national and intra-national diversity," Journal of International Business Studies, vol. 39, no. 1, pp. 41-46, 2008.

[14] D. Brown, "Feds miss minority hiring targets," Canadian HR Reporter, vol. 17, no. 11, pp. 1-9, 2004.

[15] H. C. Jain and J. J. Lawler, "Visible minorities under the Canadian employment equity Act, 1987-1999," Relations Industrielles, vol. 59, no. 3, pp. 585-609, 2004.

[16] D. Oliver, "Achieving results through diversity: a strategy for success," Ivey Business Journal Online, vol. 69, no. 4, 2005.

[17] D. A. Thomas and R. J. Ely, "Making difference matter: a new paradigm for managing diversity," Harvard Business Review, vol. 74, no. 5, pp. 79-90, 1996.

[18] T. M. Sintonen and T. Takala, "Racism and ethics in the globalized business world," International Journal of Social Economics, vol. 29, no. 11, pp. 849-860, 2002.

[19] R. Trichur, Conference Board of Canada Report. Employment Equity Still Failing Minorities, Canadian Press Newswire, Toronto, Canada, 2004. 
[20] F. Henry and C. Tator, The Color of Democracy: Racism in Canadian Society, Nelson, Toronto, Canada, 2006.

[21] V. Dugale, "The changing color of Canada," Our Times, vol. 25, no. 5, pp. 24-28, 2006.

[22] J. Y. Yee and G. C. Dumbrill, "Whiteout: looking for race in Canadian social work practice," in Multicultural Social Work in Canada: Working With Diverse Ethno-Racial Communities, A. Al-Krenaw and J. R. Graham, Eds., pp. 98-121, Oxford University Press, Don Mills, Canada, 2003.

[23] R. Robin, "Delivering diversity," Canadian Business, vol. 77, no. 7, p. 38, 2004.

[24] K. Pendakur and R. Pendakur, "Colour my world: have earnings gaps for Canadian-born ethnic minorities changed over time?" Canadian Public Policy, vol. 28, no. 4, pp. 489-511, 2002.

[25] A. Jackson, Poverty and Racism, Canadian Council on Social Development, Ottawa, Canada, 2001.

[26] J. Samuel and K. Basavarajappa, "The visible minority population in Canada: a review of numbers, growth and labor force issues," Canadian Studies in Population, vol. 33, no. 2, pp. 241269, 2006.

[27] Statistics Canada, The Ethnic Diversity Survey: Portrait of a Multicultural Society, (Section on Visible Minority and Discrimination or Unfair Treatment), Catalogue No. 89-593XIE, StatsCan, Ottawa, Canada, 2003.

[28] Statistics Canada, Visible minorities in the Canadian labor force, 1991, http://www.statcan.gc.ca/studies-etudes/75001/archive/1991/5018456-eng.pdf.

[29] Statistics Canada, Labor Force Activity, Visible Minority Groups, Immigrant Status and Period of Immigration, Highest Certificate, Diploma or Degree, Age Groups, and Sex for the Population 15 Years and Over of Canada, Provinces, Territories, Census Metropolitan Areas and Census Agglomerations, 2006 Census-20\%Sample Data, 2006, http://www12.statcan.gc.ca/census-recensement/2006/dp-pd/ tbt/Rp-eng.cfm?LANG=E\&APATH=3\&DETAIL $=0 \& D I M=0 \&$ $\mathrm{FL}=\mathrm{a} \& \mathrm{FREE}=0 \& \mathrm{GC}=0 \& \mathrm{GID}=0 \& \mathrm{GK}=0 \& \mathrm{GRP}=1 \& \mathrm{PID}=$ 93716\&PRID $=0 \& \mathrm{PTYPE}=88971,97154 \& \mathrm{~S}=0 \&$ SHOWALL $=0$ $\& \mathrm{SUB}=741 \&$ Temporal $=2006 \&$ THEME $=74 \& \mathrm{VID}=0 \&$ VNAMEE $=\& V N A M E F=$.

[30] CLC (Canadian Labor Congress), A Workplace that Works, Canadian Labor Congress, Ottawa, Canada, 2002.

[31] Human Resources and Skills Development Canada (HRSDC), Employment Equity Act: Annual Report , 2008, http://www.hrsdc.gc.ca/eng/labour/equality/employment equity/tools/annual_reports/2008/docs/2008report.pdf.

[32] The Diversity Institute in Management and Technology, DiverseCity Counts: A Snapshot of Diversity in the Greater Toronto Area, 2009, http://www.ryerson.ca/ diversity/news/CountsReport_CONFIDENTIAL.pdf.

[33] Catalyst Canada and the Diversity Institute, Career advancement in corporate Canada: A focus on visible minoritiessurvey findings, 2007, http://www.ryerson.ca/diversity/media/ Full\%20Report.pdf.

[34] A. P. Brief, R. T. Buttram, R. M. Reizenstein et al., "Beyond good intentions: the next steps toward racial equality in the American workplace," Academy of Management Executive, vol. 11, no. 4, pp. 59-72, 1997.

[35] E. A. Deitch, A. Barsky, R. M. Butz, S. Chan, A. P. Brief, and J. C. Bradley, "Subtle yet significant: the existence and impact of everyday racial discrimination in the workplace," Human Relations, vol. 56, no. 11, pp. 1299-1324, 2003.

[36] S. Fox and L. E. Stallworth, "Racial/ethnic bullying: exploring links between bullying and racism in the US workplace,"
Journal of Vocational Behavior, vol. 66, no. 3, pp. 438-456, 2005.

[37] S. Jeanquart-barone and U. Sekaran, "Institutional racism: an Empirical Study," Journal of Social Psychology, vol. 136, no. 4, pp. 477-482, 1996.

[38] The Dominion Institute, Ipsos-Reid Survey, Dominion Institute, Toronto, Canada, 2005.

[39] U. Vu, "Feds hiring racism officers," Canadian HR Reporter, vol. 19, no. 16, pp. 6-7, 2006.

[40] T. Lopes and B. Thomas, Dancing on Live Embers: Challenging Racism in Organizations, Between the Lines, Toronto, Canada, 2006.

[41] S. Bertone and M. Leahy, "Multiculturalism as a conservative ideology: impacts on workforce diversity," Asia Pacific Journal of Human Resources, vol. 41, no. 1, pp. 101-115, 2003.

[42] M. Boyd, "Diverse fortunes in different countries? Earnings of White and Black immigrant generations in Canada and the United States," in Proceedings of the Annual Meeting of the Population Association of America, Philadelphia, Pa, USA, March 2005.

[43] G. Jordan and C. Weedon, Cultural Politics: Class, Gender, Race and the Postmodern World, Blackwell Publishers, Oxford, UK, 1995.

[44] S. Klie, "Public service falls short on hiring minorities," Canadian HR Reporter, vol. 20, no. 3, pp. 1-2, 2007.

[45] Human Resources and Skills Development Canada, Racism-Free Workplace Strategywebsite. The Government of Canada Labour Program, 2010, http://www.hrsdc.gc.ca/ eng/labour/overviews/workplace_equality/rfws.shtml.

[46] OAS, (Organization of American States), Executive Secretariat for Integral Development-SEDI. Racism-Free Workplace Strategy, 2012, http://www.sedi.oas.org/ddse/documentos/TRABAJO/new_portfolio/Canada-DF-Racism-Free \%20Workplace\%20Strategy-ING.pdf.

[47] R. Y. Wong, S. Cheng, S. Choi et al., "Deconstructing culture in cultural competence," Canadian Social Work Review, vol. 20, no. 2, pp. 149-167, 2003.

[48] R. G. Dean, “The myth of cross-cultural competence," Families in Society, vol. 82, no. 6, pp. 623-630, 2001.

[49] C. James, Seeing Ourselves: Exploring Race, Ethnicity and Culture, Thompson Educational Publishing, Toronto, Canada, 2nd edition, 1999.

[50] S. Razack, Looking White People in the Eye, University of Toronto Press, Toronto, Canada, 1999.

[51] J. Solomos and L. Back, Racism and Society, St. Martin's Press, New York, NY, USA, 1996.

[52] R. Bendl, A. Fleischmann, and C. Walenta, "Diversity management discourse meets queer theory," Gender in Management, vol. 23, no. 6, pp. 382-394, 2008.

[53] B. D. Metcalfe and C. Woodhams, "Critical perspectives in diversity and equality management," Gender in Management, vol. 23, no. 6, pp. 377-381, 2008.

[54] A. Risberg and A. M. Søderberg, "Translating a management concept: diversity management in Denmark," Gender in Management, vol. 23, no. 6, pp. 426-441, 2008.

[55] J. Wrench, "Diversity management can be bad for you," Race \& Class, vol. 46, no. 3, pp. 73-84, 2005.

[56] A. Lorbiecki and G. Jack, "Critical turns in the evolution of diversity management," British Journal of Management, vol. 11, no. 3, pp. S17-S31, 2000.

[57] P. Zanoni and M. Janssens, "Deconstructing difference: the rhetoric of human resource managers' diversity discourses," Organization Studies, vol. 25, no. 1, pp. 55-74, 2004. 
[58] G. J. Dei, "Critical perspectives in antiracism: an introduction," Canadian Review of Sociology and Anthropology, vol. 33, no. 3, pp. 247-267, 1996.

[59] J. Sorenson, "I'm not a racist, and nobody I know is either. A worthy statement which invites discussion of 'colorblindness," in Culture of Prejudice, J. C. Blackwell, M. E. G. Smith, and J. S. Sorenson, Eds., pp. 47-52, Broadview Press, Peterborough, Canada, 2003.

[60] B. Trenerry, H. Franklin, and Y. Paradies, Preventing RaceBased Discrimination and Supporting Cultural Diversity in the Workplace (An Evidence Review: Full Report), Victoria Health Promotion Foundation, Melbourne, Australia, 2012.

[61] D. M. Griffith, E. L. Childs, E. Eng, and V. Jeffries, "Racism in organizations: the case of a county public health department," Journal of Community Psychology, vol. 35, no. 3, pp. 287-302, 2007.

[62] D. M. Griffith, M. Yonas, M. Mason, and B. E. Havens, "Considering organizational factors in addressing health care disparities: two case examples," Health Promotion Practice, vol. 11, no. 3, pp. 367-376, 2010.

[63] S. Leiderman and D. M. Dupree, Looking Back: Project Change From 1991-2005, Center for Assessment and Policy Development (CAPD), Conshohocken, Pa, USA, 2005, http://www.capd.org/pubfiles/pub-2005-04-01.pdf.

[64] Seattle Office for Civil Rights, Race and Social Justice Initiative Report 2008: Looking Back, Moving Forward, 2008, http://www.seattle.gov/rsji/docs/090120rsjiReport.pdf.

[65] Seattle Office for Civil Rights, Race and Social Justice Initiative: Accomplishments 2009-2011, Office for Civil Rights, Seattle, Wash, USA, 2011, http://www.seattle.gov/rsji/docs/ RSJIAccomplishments2009-2011.pdf.

[66] Seattle Office for Civil Rights, RSJI'S New Three-Year Plan: 2012-2014 Plan focuses on Community Partnerships, 2012, http://www.seattle.gov/rsji.

[67] L. M. Johnson, B. F. Antle, and A. P. Barbee, "Addressing disproportionality and disparity in child welfare: evaluation of an anti-racism training for community service providers," Children and Youth Services Review, vol. 31, no. 6, pp. 688-696, 2009.

[68] Y. Paradies, L. Chandrakumar, N. Klocker et al., Building on Our Strengths: A Framework to Reduce RaceBased Discrimination and Support Diversity in Victoria -Full Report, Victorian Health Promotion Foundation, Melbourne, Australia, 2009, http://www.vichealth .vic.gov.au/Programs-and-Projects/Freedom-from-discrimination/Building-on-our-strengths.aspx.

[69] A. N. Miller and T. M. Harris, "Communicating to develop white racial identity in an interracial communication class," Communication Education, vol. 54, no. 3, pp. 223-242, 2005.

[70] J. Blackwell, M. Smith, and J. Sorenson, "Indians shouldn't have any special rights: belief that aboriginal peoples are 'just another minority group," in Culture of Prejudice: Arguments in Critical Social Science, pp. 121-126, Higher Education University of Toronto Press, Toronto, Canada, 2008.

[71] L. T. Smith, Decolonizing Methodologies: Research and Indigenous Peoples, Zed Books, London, UK, 1999.

[72] J. Blackwell, M. Smith, and J. Sorenson, "Immigrants are threatening our way of life," in Culture of Prejudice: Arguments in Critical Social Science, pp. 53-58, Higher Education University of Toronto Press, Toronto, Canada, 2008. 


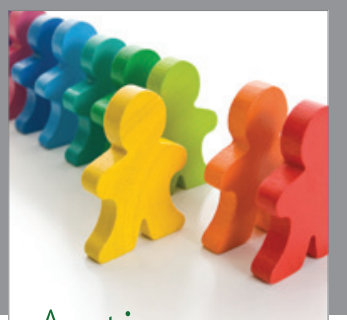

Autism

Research and Treatment
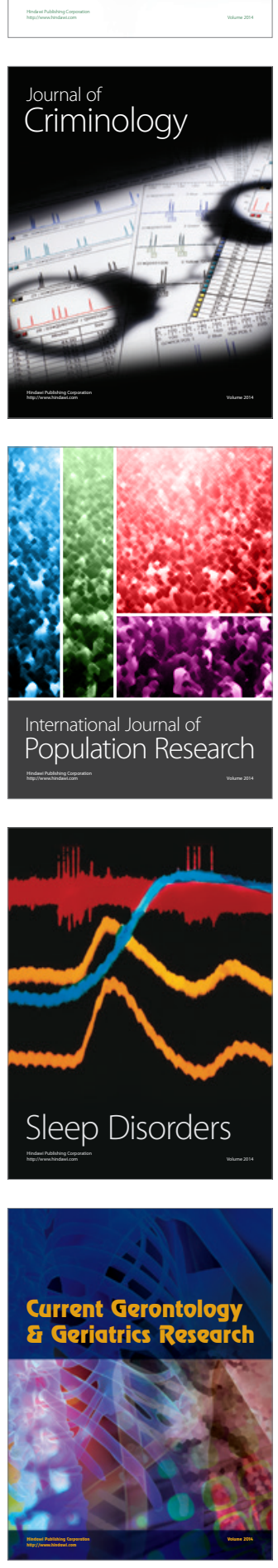
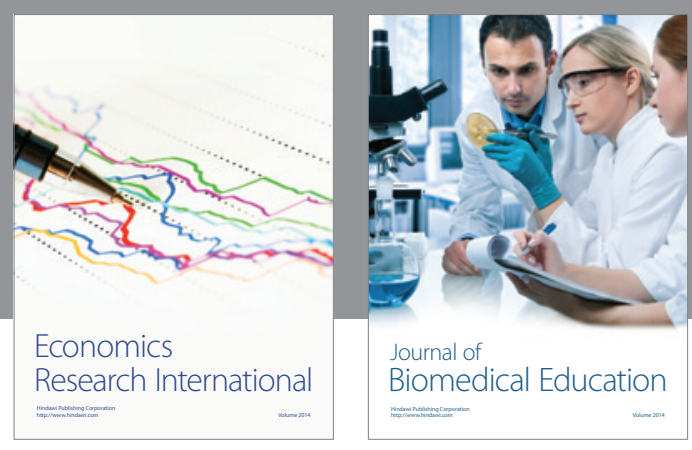

Journal of

Biomedical Education

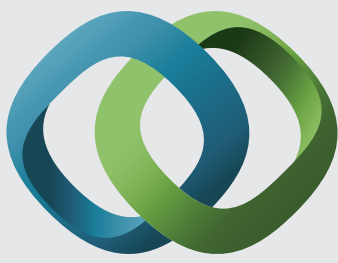

\section{Hindawi}

Submit your manuscripts at

http://www.hindawi.com
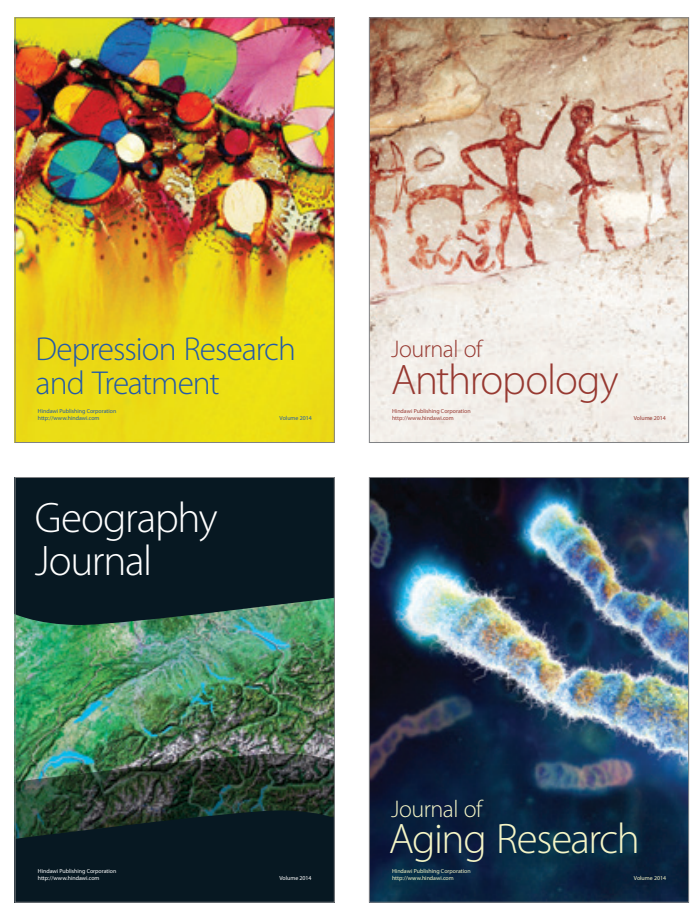

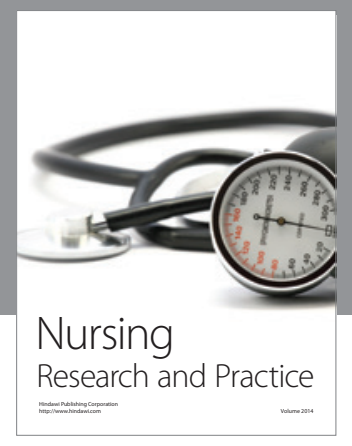

Nursing

Research and Practice

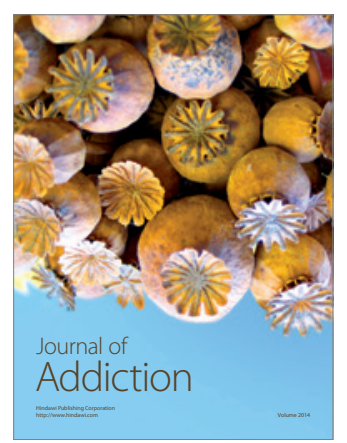

Child Development

Research

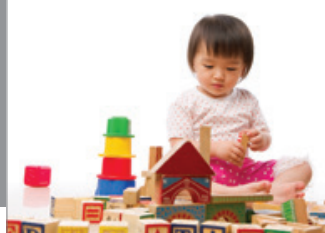

迥
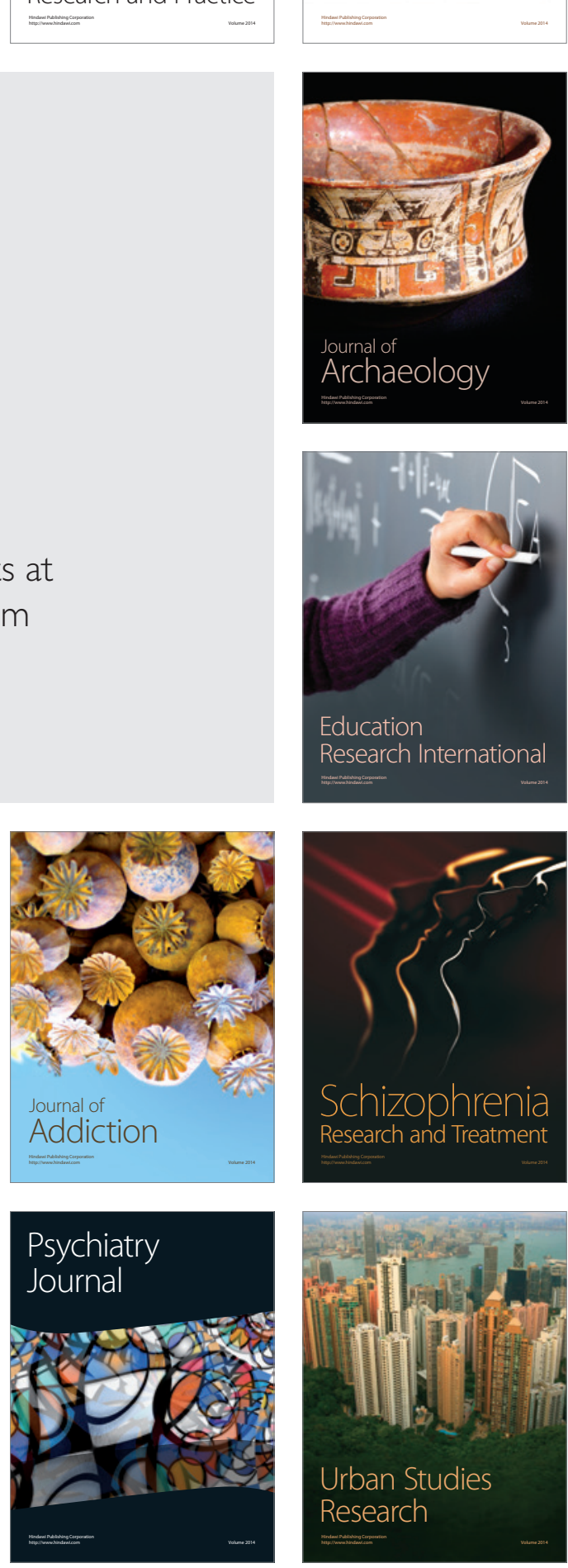